\title{
Tribological Behavior of Stellite 720 Coating under Block-on-Ring Wear Test
}

\author{
Rong Liu ${ }^{1 *}$, Qi Yang ${ }^{2}$, Feng Gao ${ }^{1}$ \\ ${ }^{1}$ Department of Mechanical and Aerospace Engineering, Carleton University, Ottawa, Canada; ${ }^{2}$ Institute for Aerospace Research, \\ National Research Council Canada, Ottawa, Canada. \\ Email: *rliu@mae.carleton.ca, qi.yang@nrc-cnrc.gc.ca, fgao1@connect.carleton.ca
}

Received July 29 ${ }^{\text {th }}$, 2012; revised August 29 $9^{\text {th }}$, 2012; accepted October $1^{\text {st }}, 2012$

\begin{abstract}
Stellite 720 is a high-carbon Co-Cr-Mo alloy, designed for severe wear/corrosion environments. This article presents a study of the Stellite 720 coating on stainless steel 304 under block-on-ring wear test. The coating is deposited through a slurry/powder metallurgy sintering process. Micro-hardness indentation test is conducted on the cross section of the coating specimen to investigate the hardness of individual phases of the coating material and the dilution effect of the substrate material on the coating layer. The tribological behavior of the coating under low and high-load wear is investtigated. The worn surfaces of the coating specimens are analyzed using a Philips XL30S FEG scanning electron microscope (SEM) with an EDAX energy dispersive X-ray (EDX) spectroscopy system. The experimental results are discussed to explore the wear mechanisms of the Stellite 720 coating under block-on-ring wear.
\end{abstract}

Keywords: Stellite Alloy; Block-on-Ring; Friction; Wear

\section{Introduction}

Stellite alloy is a group of cobalt-based Cr-W-C or CrMo-C alloys as wear-resistant, corrosion-resistant, and/or heat-resistant materials [1]. Many of the properties of the alloys arise from the crystallographic nature of cobalt (in particular its response to stress), the solid-solutionstrengthening effects of chromium, tungsten, and molybdenum, the formation of metal carbides, and the corrosion resistance imparted by chromium [2]. Generally the softer and tougher compositions are used for high-temperature applications such as gas-turbine vanes and buckets. The harder grades are used for resistance to wear. Carbon content influences hardness, ductility, and resistance to abrasive wear of Stellite alloys. The chief difference among the individual Stellite alloys is carbon content and, thus, carbide volume fraction in the materials. For example, at a carbon level of $2.4 \mathrm{wt} \%$ (Stellite 3 ), the carbides constitute about $30 \mathrm{wt} \%$ of the material. These are of the $\mathrm{M}_{7} \mathrm{C}_{3}$ (Chromium-rich primary) and $\mathrm{M}_{6} \mathrm{C}$ (tungsten-rich eutectic) types, where $\mathrm{M}$ represents the metal components. At $1 \mathrm{wt} \%$ carbon (Stellite 6B), the carbides constitute approximately $13 \mathrm{wt} \%$ of the material, these being predominantly chromium-rich eutectic carbides of the $\mathrm{M}_{7} \mathrm{C}_{3}$ type [1]. Stellite alloys can conventionally be categorized as high-carbon alloys designed for wear service; low-carbon alloys for high temperature

${ }^{*}$ Corresponding author. service; and low-carbon alloys to combat corrosion or simultaneous corrosion and wear. For carbon contents lower than $2 \mathrm{wt} \%$, these alloys are hypo-eutectic with primary face-centred cubic (fcc) cobalt dendrites surrounded by a network of eutectic $\mathrm{M}_{7} \mathrm{C}_{3}$ carbides. For carbon contents higher than $2.5 \mathrm{wt} \%$, they are hypereutectic and consist of primary $\mathrm{M}_{7} \mathrm{C}_{3}$ carbides in an interdendritic eutectic matrix [3].

As the typical application of Stellite alloys, the tribological properties of these alloys have been studied by many researchers. For example, Frenk and Wagnière [3] conducted a dry-sliding wear test on Stellite 6, using a pin-on-disc (90\% WC - 10\% Co in weight) tribometer. The results demonstrate that the dry-sliding wear of Stellite 6 against a hard metal counterface can results from at least two mechanisms. Mild wear occurs at low loads or low sliding velocities, leading to the formation of oxide debris. With higher loads or elevated sliding velocities, a transition to a severe metallic wear regime occurs, requiring the nucleation and propagation of cracks for the formation of wear debris. Frenk and Kurz [4] investigated the influence of microstructure on the wear properties of Stellite 6. The drying-sliding wear test against a much harder mating material $(90 \%$ WC - 10\% Co in weight) showed that under a severe metallic wear regime, the wear rate was independent of the microstructure (size and volume fraction of the phases). Cavitation erosion 
behaviour of Stellite alloys was studied by Heathcock et $a l$. [5]. It was shown that Stellite 3 had the highest resistance to erosion; Stellite 6 had the lowest and Stellite 20 had the similar erosion resistance to Stellite 6 . The studies in the effects of yttrium addition on the high-temperature wear behaviour of Stellite alloys [6-8] showed that the wear losses of the specimens under pin-on-disc wear test increased with the increase of specimen temperature. Among these alloys, the wear loss of Y-free specimen was the largest. Addition of yttrium enhanced the wear resistance of the alloy at elevated temperatures. However, excessive level of Y had a detrimental effect on the wear resistance. The effect of silicon addition in Stellite 6 on its hardness and wear resistance at elevated temperatures was studied by Celik and Kaplan [9]. They found that the hardness of Stellite 6 was enhanced by the addition of $\mathrm{Si}$ and the wear resistance of Stellite 6 increased with silicon addition at low temperatures (below $100^{\circ} \mathrm{C}$ ) but decreased at high temperatures. It was also observed that the wear resistance of the material decreased with the increase of specimen temperature.

However, due to the large family, many Stellite alloys have not been studied. For example, no any data of tribological properties for wear-resistant Stellite 720 have been reported in literature, while the lack of these data has limited the application of this alloy, because a material may behave differently with the wear load level. The present research investigated the tribological behavior of Stellite 720 coating under block-on-ring sliding-wear test, ASTM G77-98. This test is a standard test method for ranking resistance of materials to sliding wear. There are several distinct types of wear which generally fall into three main categories: abrasive wear, sliding wear and erosive wear. Of the three major types of wear, sliding is the most complex, in the way different materials respond to sliding conditions. The present research was focussed on the variation of the tribological behavior of the alloy coating with the wear load and thereby investigated the wear mechanisms.

\section{Experimental Details}

\subsection{Coating Specimen}

The specimens tested in this research were Stellite 720 coating on stainless steel 304 substrate, which were provided by Kennametal Stellite. The composition of Stellite 720 consists of $33 \% \mathrm{Cr}, 18 \%$ Mo and $2.45 \%$ C (in weight, Co in balance). The hardness of the alloy is about HRC55. Stellite 720 is one of the members of the newly developed Stellite 700 series. By replacing tungsten in the Stellite alloys with molybdenum, these new alloys have increased wear resistance, as well as exceptionally high corrosion resistance in reducing atmospheres.
The coating specimens were fabricated with a slurry/ sintering process. The slurry was a mixture consisting of Stellite 720 powder, water, binder, boric acid, de-foamer and ammonia. The stainless steel 304 plate was dipped into the slurry, hung with a clip. The coated plate was then sintered in a vacuum furnace at $1200^{\circ} \mathrm{C}$ for $3 \mathrm{hr}$. The coating thickness after the surface polishing was about $500 \mu \mathrm{m}$. The microstructures of the specimen cross section were examined using SEM; the image is presented in Figure 1.

The coating microstructure of Stellite 720 consists of primary $\mathrm{Cr}_{7} \mathrm{C}_{3}$ carbide dispersed uniformly in a Co solid solution matrix. The volume fraction of carbides in the microstructure is about 35\%. There are no obvious porosity and cracks observed in the interface between the coating layer and substrate, which implies good bonding of the interface.

\subsection{Microhardness Test}

Micro indentation test was conducted the section of the coating specimen utilizing a Microhardness Tester Unit, Model SMT-X7 Dual Indenter. The purposes of this test are two: one is to measure the hardness of the carbide phase and the hardness of the solid solution matrix individually; the other is to investigate the hardness variation across the coating/substrate interface. This model of microhardness tester unit is fully-automated with a computer-controlled motorized turret, and compatible with both Vickers indenter and Knoop indenter. It has a software interfaced dial, from $1 \mathrm{gf}$ to the load capacity of 2000 gf. The load duration can vary between 5 - 60 s, controlled by an automatic loading, duration and unloading

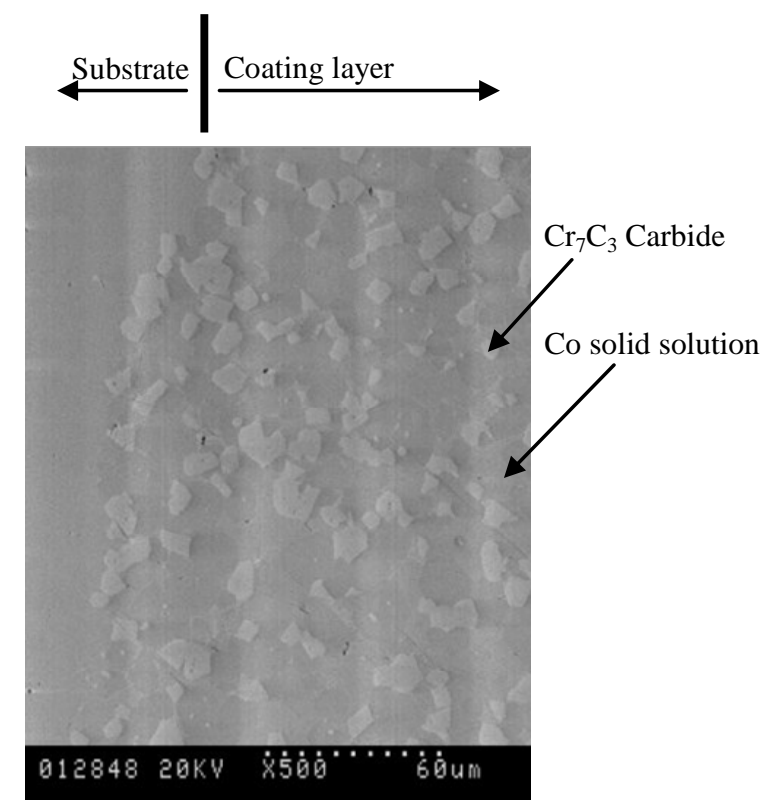

Figure 1. Microstructure of coating specimen cross section. 
system. With a microscope equipped, each individual phase in a microstructure can be identified and selected to measure. The apparatus applies a constant force to a sharp indenter that permanently indents the specimen material. The hardness value is automatically computed by a built-in software package based upon the area of the indentation left in the specimen and the force applied. For Vickers hardness, the value is calculated based on the measurement of the diagonals of the indention under a set load. The indentation load was selected based on the hardness of the tested material and the size of the area to be measured. The indentation load used in this research was 100 gf.

Ten tests were made on the carbide phase and the solid solution phase, respectively; the average hardness values are HV1251 for the carbide phase and HV553 for the solid solution matrix. It is clear that the carbide phase is doubly harder than the solid solution. To investigate hardness variation across the coating/substrate interface, three paths in the coating specimen cross section were selected to measure. For the indentation on the coating material, each test was tried to cover both the carbide and solid solution phases so that obtained hardness value may represent the average of the carbide hardness and the solid solution hardness. However, it should be explained that, since the indentation on the coating material could not cover exactly equal amount for the two phases, the measured data may deviate from the real average hardness and vary from each test, as shown in Figure 2; the three curves represent the three tests along the three paths, respectively. From the indentation results, it is evident that there is a diffusion layer at the interface and the region of the coating about $100 \mu \mathrm{m}$ from the interface was influenced by the substrate material, which is characterized by the dropped hardness.

\subsection{Block-on-Ring Wear Test}

The tribological behavior of the Stellite 720 coating was investigated using a Falex Block-on-Ring machine, in terms of the ASTM G77-98 Testing Standard. The wheel

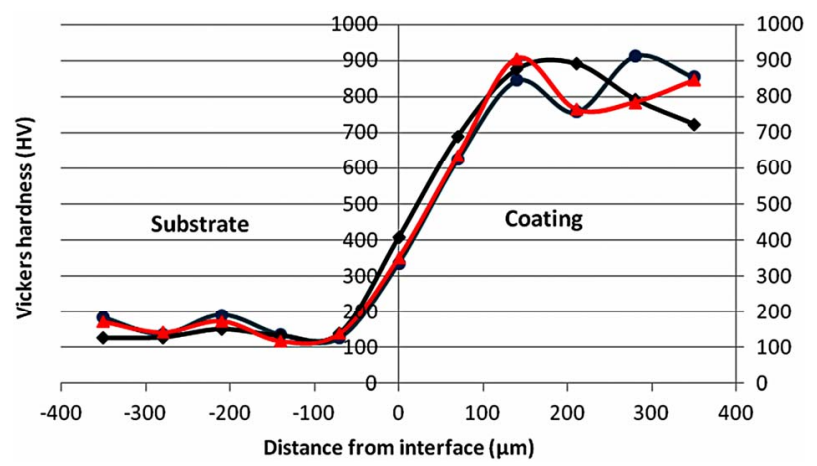

Figure 2. Hardness variation across coating/substrate interface. was made of 4620 steel (Falex S-10 ring) hardened to HRC58 to HRC63. The coating/substrate specimen was a block with the dimension of $14.5 \times 6.35 \times 10.16 \mathrm{~mm}$. Three specimens were tested at each load and six load levels (from $267 \mathrm{~N}$ or $60 \mathrm{lb}$ to $1112 \mathrm{~N}$ or $250 \mathrm{lb}$ ) were tested. The test parameters were selected as below: in unlubricated condition, wheel speed of $80 \mathrm{rpm}$, test duration of 25 min (2000 revolutions). During the test the stationary block specimen was pressed with a constant force against a rotating ring specimen at $90^{\circ}$ to the ring's axis of rotation. Friction between the sliding surfaces of the block and ring resulted in loss of material from both pieces. The test was run at ambient temperature, but due to friction heat the specimen temperature increased with duration time; which was measured in real time using a thermal couple during the test. A software control unit was employed to allow for monitoring during the test the actual dynamic normal load and friction force thus computing friction coefficient in real-time.

\section{Results and Discussion}

\subsection{Friction Coefficient}

Under each load three specimens were tested so that three curves of friction coefficient versus time were obtained. Figure 3 presents one of them for each load level as examples. It is shown that for all the load cases the friction coefficient increased quickly at the initial stage (within $50 \mathrm{~s}$ ), then it fluctuated in a period of about $100 \mathrm{~s}$, and finally it reached a constant at the stable stage. The averages of three friction coefficients taken at the stable stage under each load are summarized in Figure 4.

It is shown that the friction coefficient of Stellite 720 coating against Falex S-10 ring did not vary with the wear load; the friction coefficients measured under the five load levels are between $0.44-0.45$. This can be explained because friction coefficient is a material property and it should be independent of load.

\subsection{Wear Loss}

The wear resistance of each specimen was estimated by the volume loss of the specimen material, which is represented by the volume of the wear track. For each wear track four cross sections were selected to obtain the profile utilizing a D150 Surface Profile Measuring System, as illustrated in Figure 5. The cross-sectional areas were calculated automatically based on the corresponding cross section profiles by the software associated with the D150 Surface Profile Measuring System. Figure 6 provides one of the cross section profiles for each load level as examples.

The volume of each wear track was calculated as the average area of the four measured cross sections multiplied by the length of the wear track $(6.35 \mathrm{~mm})$, and then 


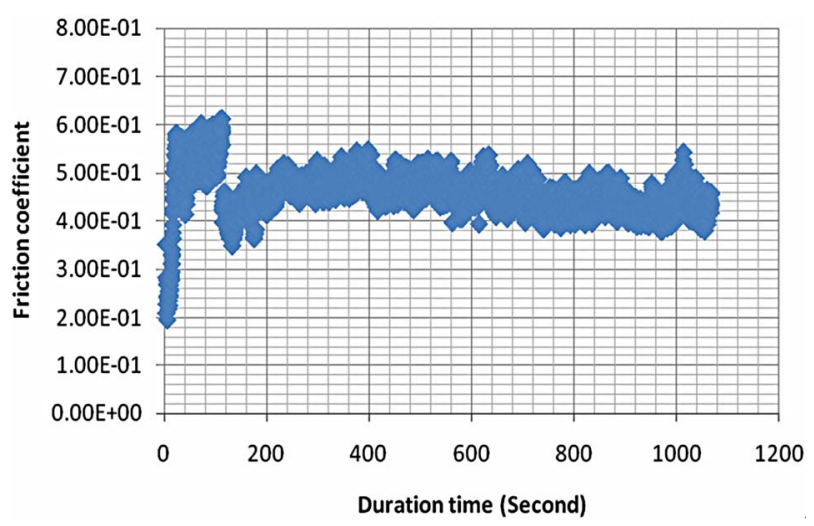

(a)

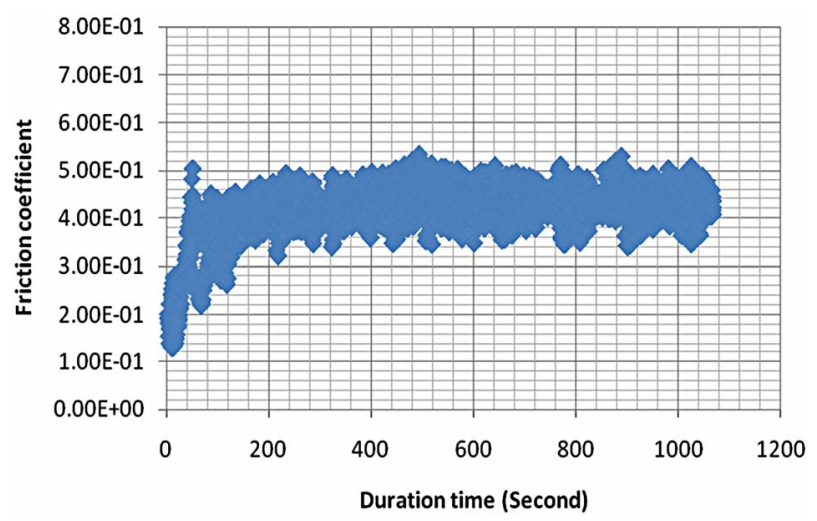

(b)

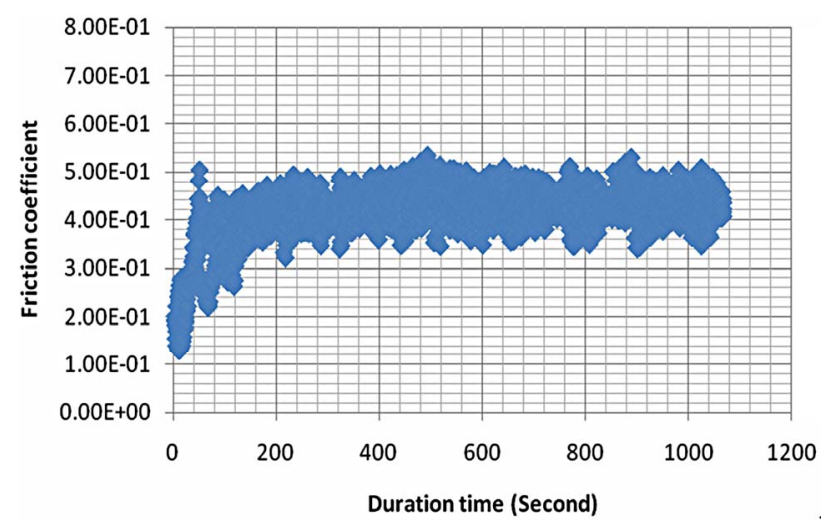

(c)

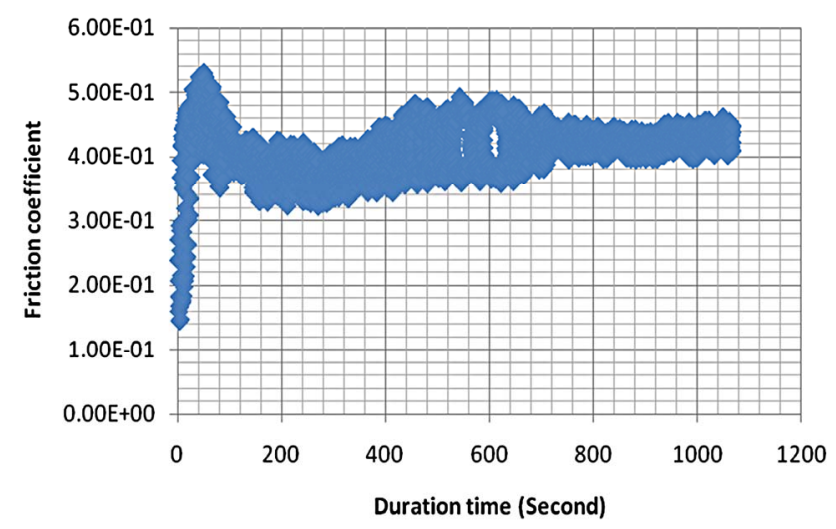

(d)

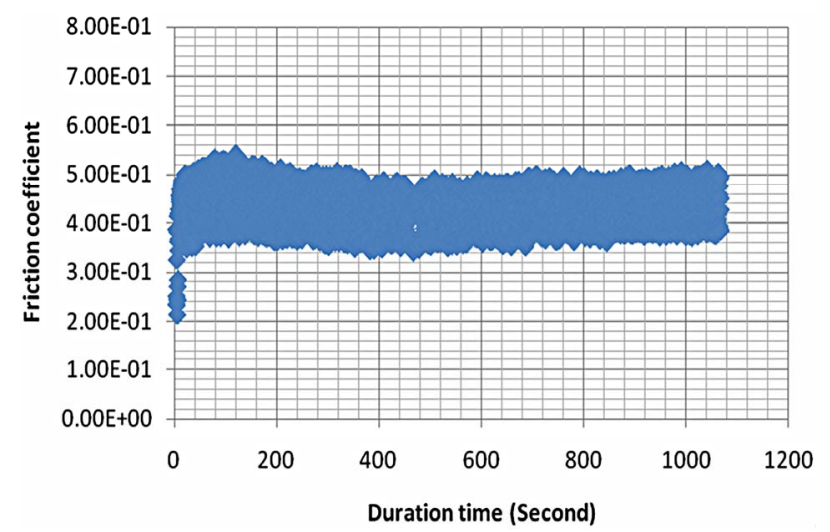

(e)

Figure 3. Friction coefficient variation with duration time of Stellite 720 coating against Falex S-10 ring under a load of (a) $267 \mathrm{~N}$, (b) $400 \mathrm{~N}$, (c) $667 \mathrm{~N}$, (d) $934 \mathrm{~N}$ and (e) $1112 \mathrm{~N}$.

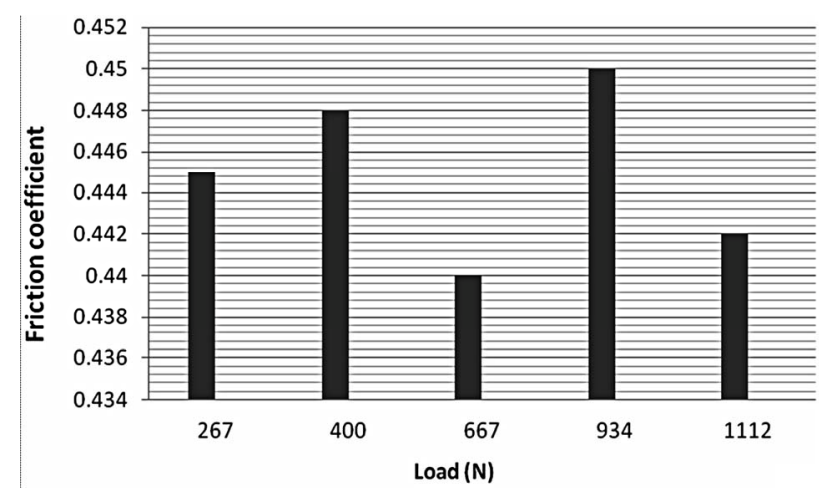

Figure 4. Friction coefficients of Stellite 720 coating against Falex S-10 ring under different levels of load.

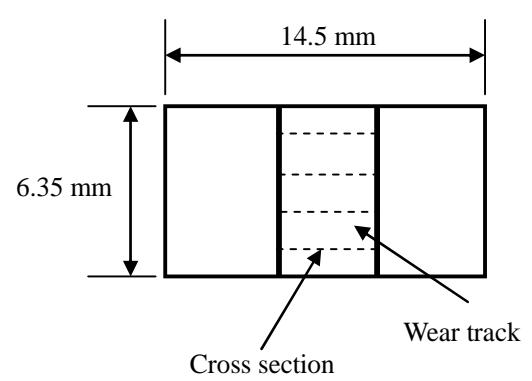

Figure 5. Schematic drawing of worn surface showing wear track.

the wear loss of the coating under each load was the average of the wear track volumes of three specimens under the test. As illustrated in Figure 7, the wear loss of the Stellite 720 coating increased with the load between 267 $\mathrm{N}$ and $667 \mathrm{~N}$, but it decreased when the load was greater than $667 \mathrm{~N}$. The errors of wear loss under each load were calculated between $8.36 \%$ - $13.6 \%$.

\subsection{Worn Surface}

In general, wear loss increases with contact load, but the 


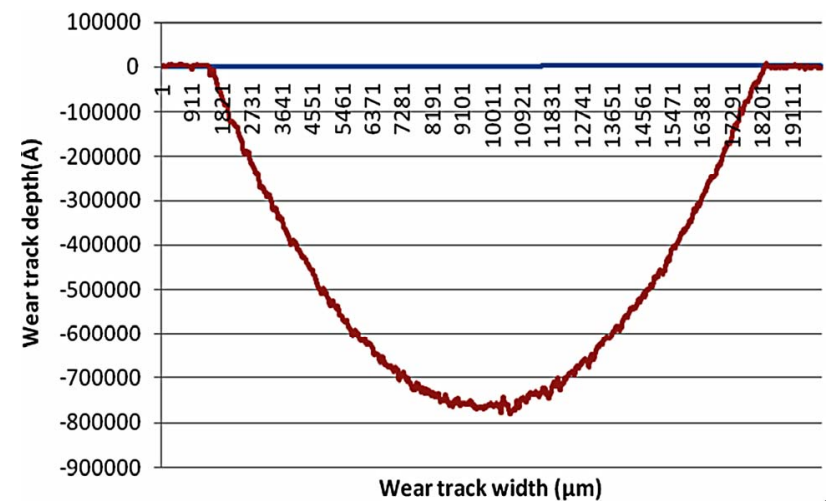

(a)

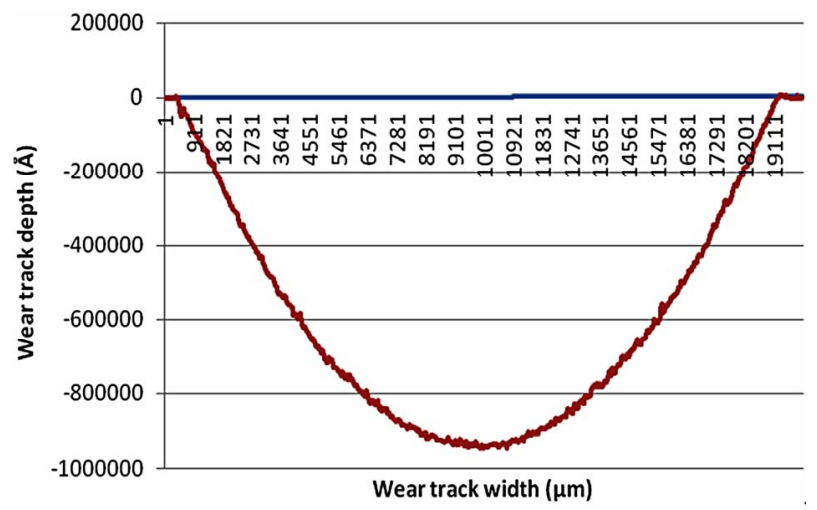

(b)

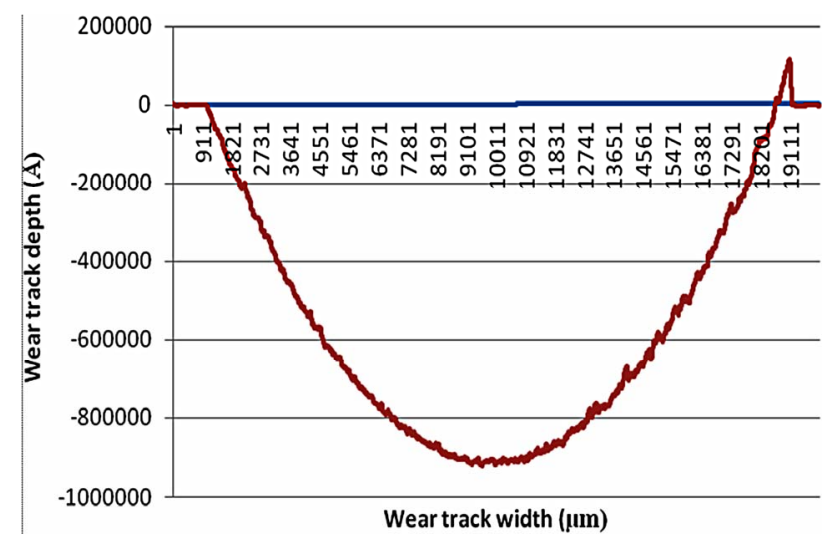

(c)

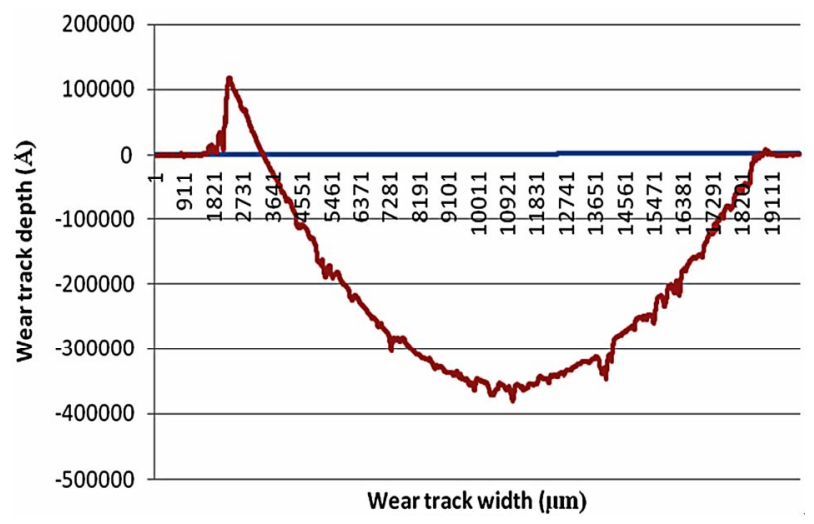

(d)

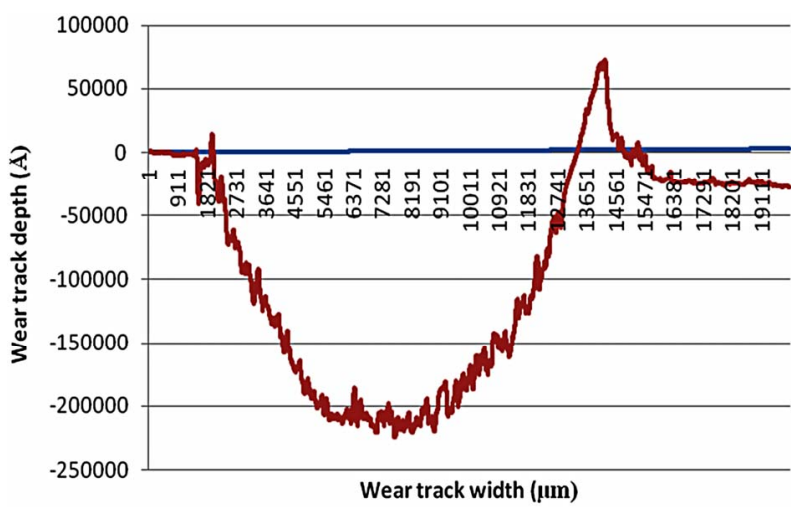

(e)

Figure 6. Cross section profiles of wear tracks induced in the block-on-ring test under (a) $267 \mathrm{~N}$, (b) $400 \mathrm{~N}$, (c) $667 \mathrm{~N}$, (d) $934 \mathrm{~N}$ and (e) $1112 \mathrm{~N}$.

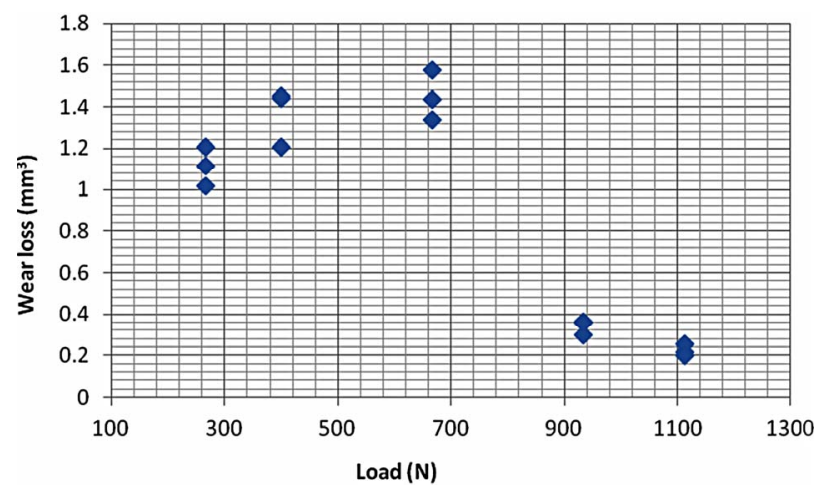

Figure 7. Wear loss versus load of Stellite 720 coating under block-on-ring wear test.

Stellite 720 coating exhibited abnormal behavior under high loads. To explain and understand the wear test results, the worn surfaces of the coating specimens were examined using SEM. It can be seen in Figure 8 that under the lower loads ( $267 \mathrm{~N}, 400 \mathrm{~N}$ and $667 \mathrm{~N}$ ) wear the worn surfaces exhibited typical ploughing characters with rugged morphology, while under the higher loads $(934 \mathrm{~N}$ and $1112 \mathrm{~N}$ ) the worn surfaces showed obvious oxidation and "glazing" features, with oxide debris observed.

As this wear test was conducted in an unlubricated condition, rubbing of the contact surfaces generated friction heat, which raised the specimen temperature with duration time. A thermal couple that was attached beneath the specimen surface recorded the temperature of the specimen in real time. The plot in Figure 9 presents the relationship between the maximum temperature (measured at the longest duration time) of the specimen and the wear load. It is clear that the specimen temperature increased with the wear load and the maximum temperatures of the specimens varied from $40^{\circ} \mathrm{C}$ to $160^{\circ} \mathrm{C}$. It should be pointed out that the real maximum 


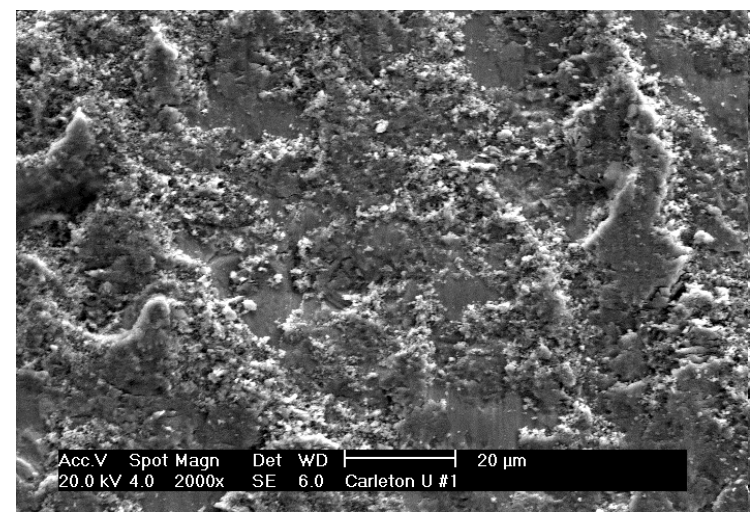

(a)

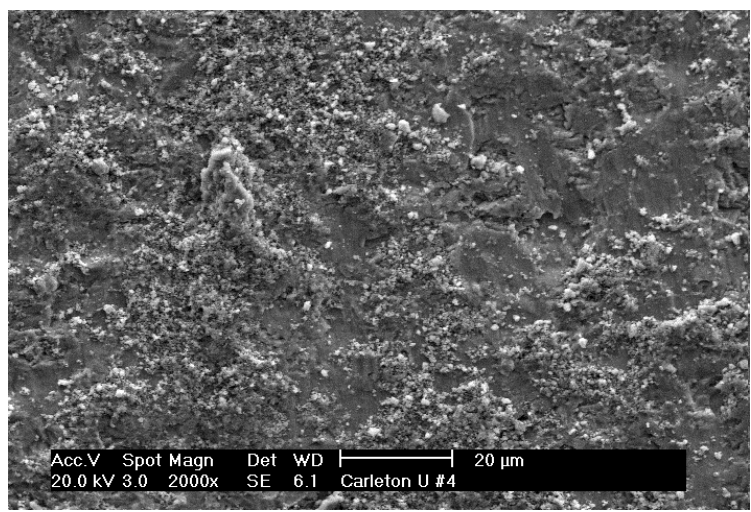

(b)

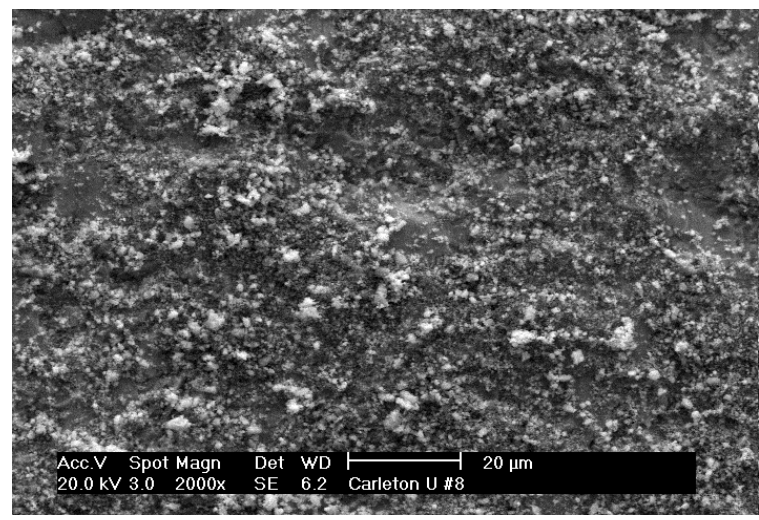

(c)

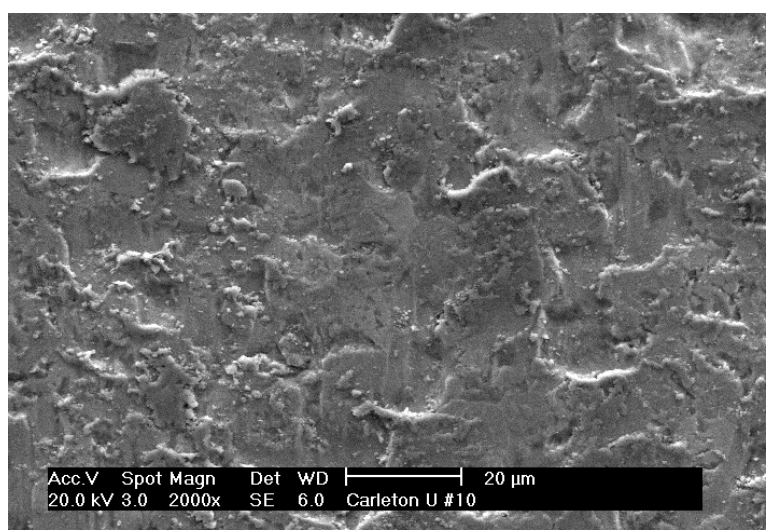

(d)

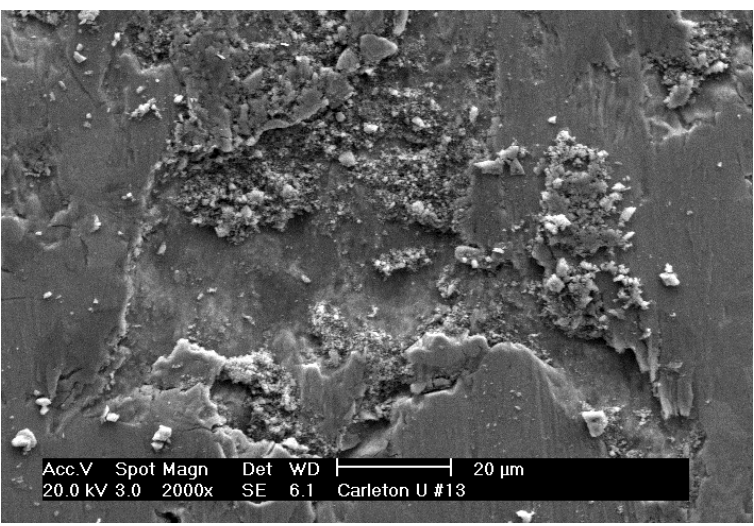

(e)

Figure 8. SEM images of worn surface of Stellite 720 coating from block-on-ring test under (a) $267 \mathrm{~N}$, (b) $400 \mathrm{~N}$, (c) $667 \mathrm{~N}$, (d) $934 \mathrm{~N}$ and (e) $1112 \mathrm{~N}$.

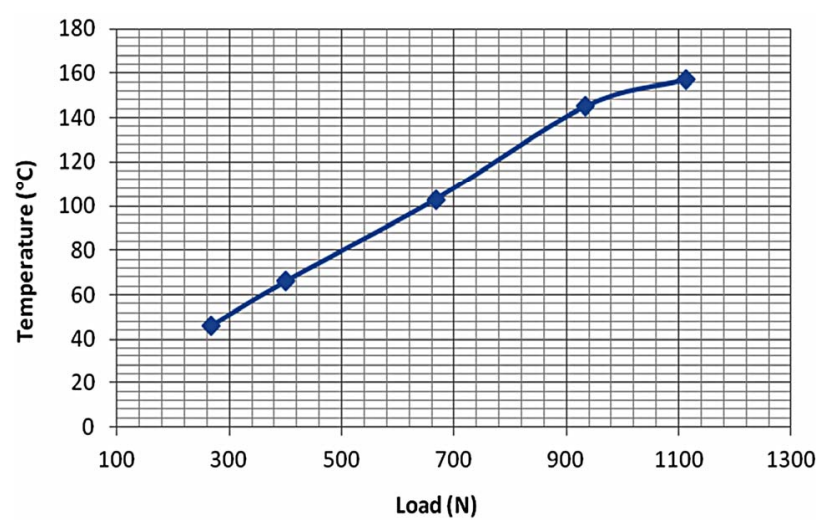

Figure 9. Maximum temperature of specimen versus load under block-on-ring wear test.

temperature of the specimen occurred at the contact surface which would be higher than the measured value. In the lower-load wear the wear resistance of the Stellite 720 coating strongly depended on its hardness. The carbides were the main contribution to the wear resistance of the Stellite 720 coating, since the hardness of the carbides is much higher than the solid solution in the alloy. With the increase of the contact load, the interaction between the two mating surfaces was enhanced, which resulted in more wear loss. However, with further increase in the contact load to a certain level (934 N), the enhanced friction of the two mating surfaces raised the specimen temperature to the level that could cause oxidation of the contact surfaces. The oxide films were brittle and easily smashed in the wear process; these oxide debris were embedded in the specimen surface by the contact load, which enhanced its hardness thus increased its wear resistance. This is so-called "glazing" hardening [10]. The morphologies of worn surface shown in Figures 8(d) and 8(e) demonstrate this feature. The composition analyses of worn surface with a Philips XL30S 


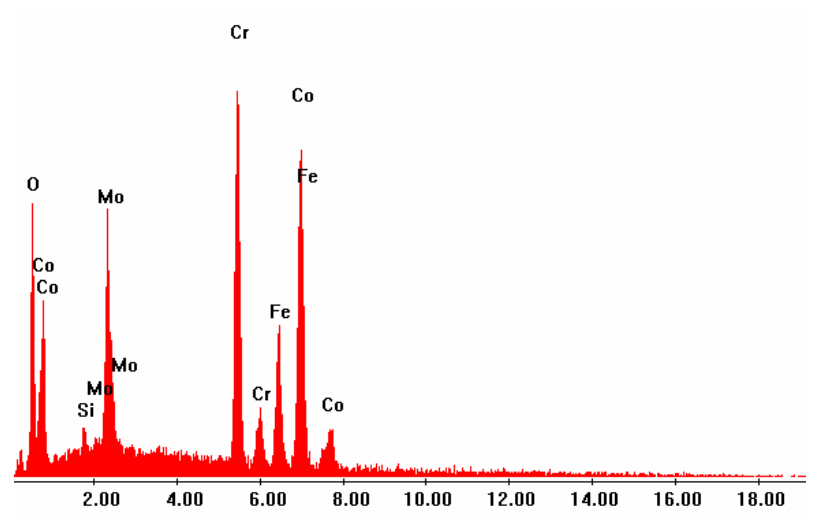

(a)

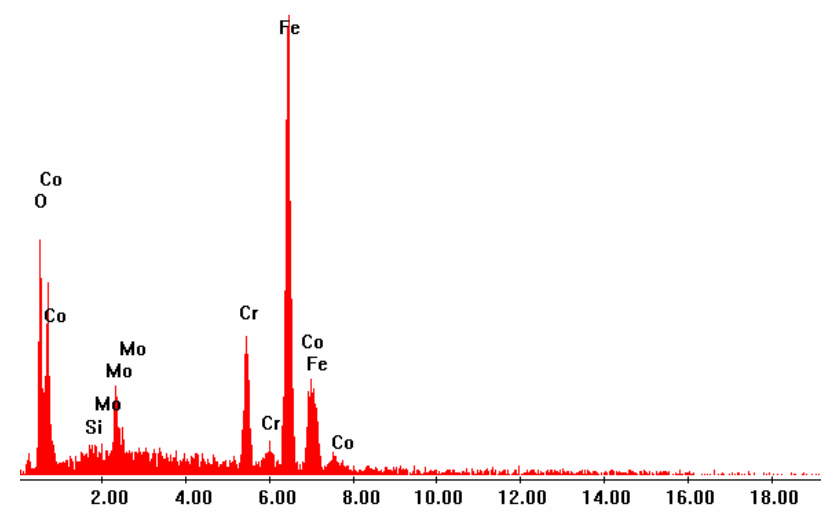

(b)

Figure. 10. EDX results of worn surface tested under: (a) low load, (b) high load.

FEG scanning electron microscope (SEM) and an EDAX energy dispersive X-ray (EDX) spectroscopy system showed that the worn surface tested under high loads contained much higher Fe than that under low loads, which came from the mating surface of Falex S-10 ring (4620 steel wheel). The high Fe resulted from two mechanisms; one was the oxide debris from the steel wheel that was embedded in the specimen surface; the other was the wear chips from the steel wheel that stuck on the specimen. The latter also occurred at low loads, as demonstrated by the EDX spectrum in Figure 10.

\section{Conclusions}

High-carbon wear-resistant Stellite 720 was deposited on stainless steel 304 substrate with the slurry/sintering technique. The microhardness test revealed that there was a diffusion layer between the coating and the substrate and the coating hardness was affected by the dilation of the substrate material in the region near the interface but the surface layer of the coating was not affected.

The friction and wear resistance of the Stellite 720 coating were investigated under block-on-ring sliding- wear test, ASTM G77-98 in an unlubricated condition. The experimental results showed that the friction coefficient of the Stellite 720 coating against Falex S-10 ring (4620 steel wheel) was nearly constant with the contact load, and around $0.44-0.45$. The wear loss of the coating increased with the load under low load wear but it decreased when the load was greater than $667 \mathrm{~N}$ (150 lb). The mechanism for the enhanced wear resistance was attributed to the so-called "glazing" hardening.

\section{Acknowledgements}

The authors are grateful for financial support from the Natural Science \& Engineering Research Council of Canada (NSERC), in-kind support form National Research Council Canada, and both financial and in-kind support of Kennametal Stellite.

\section{REFERENCES}

[1] J. R. Davis, "Nickel, Cobalt, and Their Alloys,” ASM International, Materials Park, 2000.

[2] W. Betteridge, “Cobalt and Its Alloys," Halsted Press, Chichester, 1982.

[3] A. Frenk and J. D. Wagnière, "Laser Cladding with CobaltBased Hardfacing,” Journal of Physics, Vol. IV, 1991, pp. 65-68.

[4] A. Frenk and W. Kurz, "Microstructural Effects on the Sliding Wear Resistance of a Cobalt-Based Alloy," Wear, Vol. 174, No. 1-2, 1994, pp. 81-91. doi:10.1016/0043-1648(94)90089-2

[5] C. J. Heathcock, A. Ball and B. E. Protheroe, "Cavitation Erosion of Cobalt-Based Stellite Alloys, Cemented Carbides and Surface-Treated Low Alloy Steels,” Wear, Vol. 74, No. 1, 1981, pp. 11-26. doi:10.1016/0043-1648(81)90191-5

[6] L. C. Wang and D. Y. Li, "Effects of Yttrium on Microstructure, Mechanical Properties, High-Temperature Wear Behaviour of Cast Stellite 6 Alloy,” Wear, Vol. 255, No. 1-6, 2003, pp. 535-544.

[7] I. Radu, D. Y. Li and R. Llewellyn, “Tribologocal Behaviour of Stellite 21 Modified with Yttrium,” Wear, Vol. 257, No. 11, 2004, pp. 1154-1166. doi:10.1016/j.wear.2004.07.013

[8] I. Radu and D. Y. Li, "The Wear Performance of Yttrium-Modified Stellite 712 at Elevated Temperatures," Tribology International, Vol. 40, No. 2, 2007, pp. 254265. doi:10.1016/j.triboint.2005.09.027

[9] H. Celik and M. Kaplan, "Effects of Silicon on the Wear Behavior of Cobalt-Based Alloys at Elevated Temperature,” Wear, Vol. 257, No. 5-6, pp. 606-611. doi:10.1016/j.wear.2004.03.008

[10] F. Stott, D. Lin and G. Wood, "Glazes Produced on NickelBase Alloys during High Temperature Wear,” Nature, Vol. 242, 1973, pp. 75-77. 